4. Financial support in order to pursue this unprecedented work. We have been encouraged already by a number of well-known French and international personalities who are now members of our International Committee.

There are numerous national chronologies of the environmental movement which have been revised and translated already: of Switzerland, Great Britain, Italy, Spain, Austria, Germany, Portugal, Sweden, Norway, East Europe, India, Japan, Israel, Tibet, Malaysia, Philippines... and on such organizations as Greenpeace, to be followed by others. This environmental history is a research project with international dimensions. Accordingly, we want to cover the great variety, the depth, and the long-standing activities, of environmental organizations, and demonstrate the importance of their role as precursors and stimulants of institutional measures for the environment of Humankind and Nature and particularly the present unification of Europe.

ROLAND DE MILLER
Centre national d'Etudes et de Documentation
$\quad$ sur l'Ecologie et sa Culture
(CEDEC)
Le Château
Sigoyer
F O4200 Sisteron
France.

Tel. \& Fax (33) 92621702

\title{
Sustainability of Siberian Forests
}

$S_{8}$ iberia's vast forests are not only one of the world's last great frontiers: they are a natural heritage of truly global importance. For Russia, they are a potential cornerstone of a workable economy; for the world as a whole, they are a key tool in the maintenance of a stable climate and a healthy Biosphere.

On 9 March 1992, IIASA signed an agreement with the Russian Academy of Sciences and their Ministry of Ecology and Natural Resources for a major, multi-year project on 'Forest Resources, Environment, and Socio-economic Development of Siberia'. The objectives of the project are to:

- analyse the state of Siberia's forests and develop databases on forest ecosystems and ecocomplexes from the Urals to the Pacific;

- assess the biospheric role of Siberia's forest ecosystems and ecocomplexes, especially in regard to global warming and biodiversity;

- identify strategies that will increase their contribution to sustainable socio-economic development of Siberia; and

- carry out a detailed case-study of the Ust-ilimsk region.

Siberia has five million square kilometres of forested area - an area roughly two-thirds the size of the continental United States. These forests constitute some $19 \%$ of the world's forested area and contain about $17 \%$ of the world's standing timber. Within that timber is an estimated 40,000 million tons of carbon - nearly half the amount sequestered in the forests of the Amazon Basin.

\section{Challenges for Improvement}

The changes in the former Soviet Union offer unprecedented opportunities and risks for the development of Siberia's environment, forest resources, and forest industries. In spite of its timber and mineral wealth, the region suffers from weaker economic development than other parts of Russia and a high incidence of social problems. Healthy forests and forest industries could improve the economic and social vitality of Siberia and the environmental well-being of the entire world.

Considerable effort has gone into setting up an elaborate project network. The study will involve dozens of researchers throughout Russia as well as collaborators in the USA, Canada, Japan, Finland, Sweden, and other countries. Two core research teams will be set up, one at IIASA led by the undersigned, and the other in Moscow under Alexander Isaev, Director of the Centre for Ecological and Forest Productivity Problems of the Russian Academy of Sciences.
Following initial set-up work and a preliminary analysis of available data, work began last autumn to develop two sets of databases, one of them on resources and eco$\operatorname{logy}$, and the other on industry, infrastructure, and socioeconomic factors. In 1993, work is beginning on studies of forest resources, markets, industry, and infrastructure also on regional and global ecological factors and socioeconomic aspects. Some of the studies will focus on forests' non-wood benefits, ranging from wildlife habitat and recreation to the protection of local and global climate.

The last stages of work will be integrated analyses of the subsidiary studies leading to policy recommendations for sustainable development. Current practices are anything but sustainable, and research by IIASA's Forest Resources Project indicates that, if they continue, some of Siberia's forests could be mined out in from 40 to 50 years.

\section{Vast Areas and Changes Involved}

Historically, Siberia's forest industry has been characterized by massive industrial developments. In setting up the Ust-ilimsk combine some 20 years ago, The Soviet authorities built a new town and airport, a railway line connecting the development to the Baikal-Amur railroad, and one of the largest hydroelectric power-plants in Russia, with a capacity of four million kilowatts and a reservoir of 2,000 square kilometres. The combine was assigned a wood catchment area of 36,000 square kilometres almost the size of Switzerland.

Restructuring the Siberian forest industry will be difficult and expensive, for at present the industry is characterized by obsolete technology, low productivity, and products of low quality. In addition, much of it is located far from major world markets. But in any case recommendations regarding possible industrial strategies - what to produce, how, and for whom - will be consistent with the broader goal of environmental and socio-economic sustainability.

\section{Sten Nillson, Leader \\ IIASA Forest Resources Project \\ International Institute for Applied Systems Analysis* A-2361 Laxenburg \\ Austria.}

* The International Institute for Applied Systems Analysis (IIASA) is an interdisciplinary, nongovernmental research institution sponsored by a consortium of National Member Organizations in 15 nations. The Institute conducts international and interdisciplinary scientific studies to provide timely and relevant information and options, addressing critical issues of global environmental, economic, and social, changes for the benefit of the public, the scientific community, and national and international institutions. 